\title{
APLIKASI MODEL PRINCIPAL AGENT PADA IMPLEMENTASI KEBIJAKAN WAJIB TANAM BAWANG PUTIH DI KABUPATEN LOMBOK TIMUR
}

\author{
APPLICATION OF THE PRINCIPAL AGENT MODEL IN THE \\ IMPLEMENTATION OF MANDATORY GARLIC PLANTING POLICY \\ IN EAST LOMBOK REGENCY
}

\author{
Anas Zaini ${ }^{1 *}$, Anwar ${ }^{1}$, Muhammad Zubair ${ }^{1}$, Dwi Praptomo Sudjatmiko ${ }^{1}$ \\ Suparmin $^{1}$, Ni Made Wirastika Sari ${ }^{1}$ \\ ${ }^{1}$ Program Studi Agribisnis Universitas Mataram, Mataram, Indonesia \\ *Email Penulis korespondensi:anzaekopol@gmail.com
}

\begin{abstract}
ABSTRAK
Sebagai salah satu negara importir bawang putih terbesar di dunia, dimana lebih dari 95 persen kebutuhan domestik saat ini dipenuhi dari impor, pemerintah Indonesia berupaya meningkatkan produksi bawang putih dalam negeri. Artikel ini membahas salah satu upaya peningkatan produksi bawang putih tersebut yaitu kebijakan wajib tanam bawang putih oleh importir yang bermitra dengan petani. Hubungan kemitraan tersebut kemudian dianalisis menggunakan Model Principal Agent, dimana hubungan kerja masing-masing komponen pendukung kebijakan didiskusikans dan dievaluasi secara kritis. Hak dan kewajiban para pihak (principal dan agent) dianalisis dan dievaluasi implementasinya berdasarkan kontrak Perjanjian Kerja Sama (PKS) yang telah ditandatangani, serta peran dan fungsi koordinasi pemerintah melalui dinas terkait dievaluasi berdasarkan petunjuk teknis pelaksanaan kebijakan. Hasil penelitian menunjukkan bahwa implementasi kebijakan wajib tanam oleh importir yang bermitra dengan petani bawang putih telah sesuai dengan PKS dan menguntungkan para pihak tanpa adanya moral hazard. Namun demikian peran koordinatif pemerintah sangat minimal terutama pada tahap monitoring dan pelaporan hasil.

Kata kunci: principal, agen, bawang putih, wajib, Sembalun
\end{abstract}

\begin{abstract}
As one of the largest garlic importing countries in the world, where more than 95 percent of domestic needs are currently met from imports, the Indonesian government is trying to increase domestic garlic production. This article discusses one of the efforts to increase garlic production, namely the mandatory garlic planting policy by importers in partnership with farmers. The partnership relationship is then analyzed using the Principal Agent Model, where the working relationship of each policy supporting component is discussed and evaluated critically. The rights and obligations of the parties (principal and agent) are analyzed and their implementation evaluated based on the signed Cooperation Agreement (CA), as well as the role and function of government coordination through related agencies are evaluated based on technical guidelines for policy implementation. The results showed that the implementation of the mandatory planting policy by importers who partnered with garlic farmers was in accordance with the $\mathrm{CA}$ and benefited the parties without any moral hazard. However, the coordinating role of the government is minimal, especially at the stage of monitoring and reporting results.

Key words: principal, agent, garlic, mandatory, sembalun
\end{abstract}

\section{PENDAHULUAN}

Sebagai negara importir terbesar bawang putih dunia dimana 95 persen konsumsi dalam negeri dipenuhi dari impor, Indonesia berada pada situasi yang penuh risiko. Hal ini dikarenakan perdagangan dunia bawang putih sangat tergantung pada satu negara yaitu China yang mengekspor sekitar 80 persen dari volume perdagangan bawang putih dunia. Selain itu, harga bawang putih China yang relatif murah di satu sisi dan tingginya harga bawang putih di dalam negeri di sisi lain memberikan insentif yang 
besar bagi pelaku usaha untuk melakukan importasi bawang putih. Marjin keuntungan tinggi yang diperoleh importir ini kemudian mendorong pemerintah Indonesia untuk mengintegrasikan kebijakan impor dengan upaya peningkatan produksi dalam negeri. Melalui Peraturan Menteri Pertanian (Permentan) nomor 38 tahun 2017 yang diperbarui dengan Permentan 24/2018 tentang Rekomendasi Impor Produk Hortikultura (RIPH), maka setiap pelaku usaha yang melakukan importasi bawang putih wajib melakukan penanaman bawang putih di dalam negeri minimal 5 persen dari volume impor yang dimintakan. Pengembangan bawang putih tersebut dapat dilakukan secara swadaya atau bekerjasama dengan petani. Namun karena keterbatasan kapasitas dan manajemen budidaya, para importir umumnya memilih bermitra dengan petani dalam memenuhi kewajiban tanam tersebut. Pertanyaannya kemudian adalah bagaimana implementasi dan kinerja wajib tanam yang dilakukan importir bawang putih? Dari berbagai penelusuran pustaka, pertanyaan ini absen dari perhatian para peneliti ekonomi pertanian.

Penelitian ini memiliki tujuan menemukan jawaban tentang implementasi dan kinerja wajib tanam bawang putih oleh importir di Kecamatan Sembalun, Kabupaten Lombok Timur sebagai upaya mewujudkan swasembada bawang putih nasional. Selain itu, penelitian dilakukan dengan pendekatan Model Principal Agent dimana hubungan kerja sama antar pihak umumnya menghadapi persoalan informasi yang tidak simetris sehingga berpeluang untuk terjadinya moral hazard dan adverse selection. Oleh karena itu penelitian ini selain memiliki kontribusi praktis menjawab pertanyaan penelitian, ia juga memiliki kontribusi teoritis terhadap perbaikan model.

\section{METODE PENELITIAN}

\section{Unit Analisis}

Unit analisis dalam penelitian ini adalah petani bawang putih yang tergabung dalam Kelompok Tani. Hal ini dikarenakan kontrak kerja sama dilakukan antara importir dengan ketua kelompok tani.

\section{Penentuan Responden}

Dalam penelitian ini penentuan jumlah responden dilakukan secara Quota Sampling yaitu sebanyak 30 petani yang mengusahakan bawang putih yang bermitra dengan importir. Para petani responden tersebut ditetapkan berdasarkan kriteria bahwa mereka menanam bawang putih bekerjasama dengan salah satu importir. Penentuan responden dilakukan secara simple random sampling sedangkan pengumpulan data dilakukan secara online survey menggunakan google form, menyesuaikan dengan protokol kesehatan pencegahan penyebaran Covid-19. Pengumpulan data dilakukan mulai tanggal 9 Agustus 2020 sampai 9 Desember 2020.

\section{Analisis Data}

Importir pada umumnya tidak memiliki kapasitas yang memadai dalam melakukan budidaya bawang putih. Oleh karena itu mereka bekerjasama dengan petani dalam rangka memenuhi kewajiban tanam 5 persen dari kuota impornya. Dalam konteks hubungan kerja sama ini maka implementasi kebijakan wajib tanam bawang putih oleh importir dianalisis menggunakan pendekatan principal-agent.

Model Principal Agent (PA) adalah suatu pendekatan yang berkaitan dengan pendelegasian pekerjaan, melibatkan dua pihak yang saling mempertukarkan sumberdaya. Principal sebagai pihak pertama menawarkan sejumlah sumberdaya (uang, 
barang, atau lainnya) kepada pihak kedua, agent, untuk melakukan kegiatan atau usaha guna memenuhi kepentingan pihak pertama (Braun and Guston, 2003). Model ini berkembang dalam kajian ilmu ekonomi kelembagaan dan diaplikasikan pada berbagai bidang ekonomi dan politik seperti infrastruktur (Paez-Perez and Sanchez-Silva, 2016), pendidikan (Wohlstetter, Datnow, and Park, 2008; Lane and Kivisto, 2008), lingkungan (Nuppenau, 2002), dan politik (Van Houten, 2009; Maggetti, and Papadopoulos, 2018).

Perumusan dan implementasi kerangka model PA secara umum dapat digunakan untuk menjelaskan relasi kontraktual antar aktor di sektor privat dan juga kebijakan publik (Bergman and Lane, 1990). Namun demikian berbagai rumusan dan implementasi model tersebut menghadapi persoalan yang bersumber dari informasi yang asimetris ataupun tidak lengkap seperti moral hazard dan adverse selection. Moral hazard terjadi karena informasi yang asimetris dimana setelah kontrak disepakati salah satu pihak, umumnya agent, berperilaku berbeda dan tidak sesuai dengan bunyi kontrak. Sementara itu adverse selection terjadi karena principal salah memilih mitra akibat informasi yang tidak lengkap.

Pada penelitian ini implementasi wajib tanam bawang putih dianalisis dengan menggunakan pendekatan principal-agent yang diadaptasi dari model Shavell (1979). Principal (importir) dan agent (petani) bertindak untuk memaksimumkan utiliti harapan masing-masing. Jika principal berorientasi memaksimumkan kemakmuran (pendapatan dari aktivitas impor) maka agent berorientasi pada memaksimumkan pendapatan dari kegiatan penanaman bawang putih, yang merupakan fungsi dari usaha yang dilakukan selama proses budidaya. Usaha yang dilakukan petani dapat berupa pengeluaran uang atau dinilai setara uang. Dengan demikian jika kemakmuran (wealth) dinyatakan dengan $w$, maka $V(w, e)=V(w-e)$. Produksi bawang putih merupakan fungsi dari usaha dan variabel random kondisi alam (state of nature). Semakin intensif usaha yang diakukan maka produksi secara teoritis meningkat pada kondisi alam yang tertentu. Namun demikian usaha agent dilakukan pada situasi tidak mengetahui apa yang akan terjadi dengan kondisi alam dan principal tidak memiliki cukup informasi tentang usaha yang dilakukan agent. Dengan demikian maka orientasi agent/petani dalam rangka memaksimumkan utilitinya dinyatakan dengan,

$$
E V(\varnothing, e)=\int V(\varnothing(x), e) r(x ; e) d x
$$

sementara itu utiliti harapan dari principal dinyatakan oleh,

$$
E U(\varnothing, e)=\int U(q(x)-\emptyset(x), e) r(x ; e) d x
$$

Namun karena importir bertujuan memenuhi kebijakan wajib tanam (minimal 5 persen dari kuota impor) maka fungsi utilitinya dalam hubungan kerjasama dengan petani dinyatakan sebagai

$$
E U(q(x))=\int U(x) d x
$$

Dengan demikian maka persoalan kemitraan antara importir dan petani bawang putih dari pendekatan principal-agent adalah menemukan Pareto optimal pemberian fee kepada petani (bantuan bibit, dan biaya untuk membeli sarana produksi lainnya) sedemikian rupa sehingga importir selain memperoleh bagi hasil maksimum berdasarkan surat Perjanjian Kerja Sama, yang terpenting adalah memperoleh jaminan kuota impor berdasarkan jumlah produksi yang dihasilkan agent/petani (kuota impor harapan, $q=x / 0,05=20 x$ ). Optimasi model dengan demikian dinyatakan sebagai, 
dengan kondisi (subject to)

$$
\max E U(\phi, e)
$$

$$
E V(\phi, e) \geq V^{0}
$$

Konstanta $\mathrm{V}^{0}$ ditentukan oleh posisi tawar petani terhadap importir dalam kaitanya dengan penyediaan lahan yang cocok, kapasitas tenaga kerja dan manajemen untuk melakukan budidaya bawang putih. Besarnya nilai $\mathrm{V}^{0}$ sama dengan manfaat yang hilang (benefit forgone) dari menanam bawang putih yaitu kesempatan untuk memperoleh pendapatan dari menanam komoditi alternatif lain seperti wortel atau kentang.

Keterangan notasi

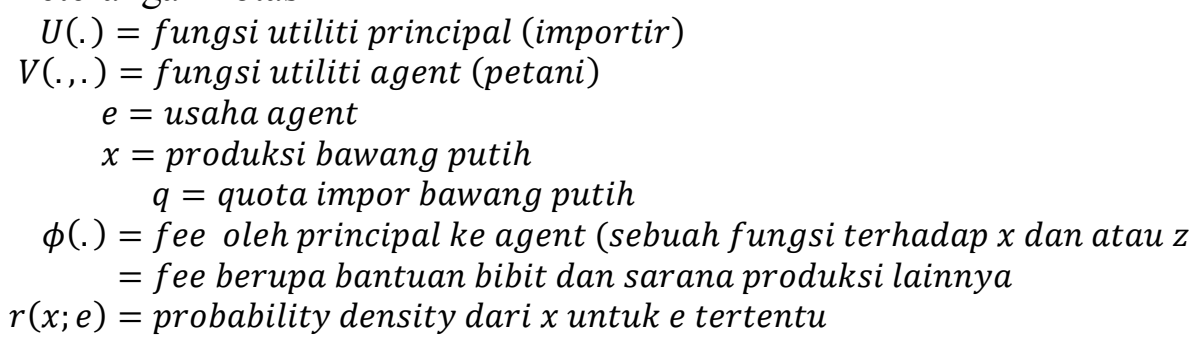

\section{HASIL DAN PEMBAHASAN}

\section{Karakteristik Responden}

Sebagian besar petani yang bermitra dengan importir dalam penanaman bawang putih adalah petani kecil yang memiliki lahan kurang dari satu hektar (93\%), bahkan sekitar 37 persen memiliki lahan kurang dari 0,5 hektar dengan irigasi sederhana. Oleh karena itu untuk mendapatkan luas penanaman yang optimal maka petani harus bergabung dalam kelompok. Para petani tersebut tergabung dalam dua kelompok tani (Poktan) yaitu Kelompok Tani Baru Mekar yang bermitra dengan PT. LBU (Lintas Buana Unggul) dan Kelompok Tani Sinar Muda yang bermitra dengan PT. KTS (Karya Tani semesta). Distribusi lengkap responden berdasarkan luas penanaman bawang putih disajikan pada gambar 1 berikut.

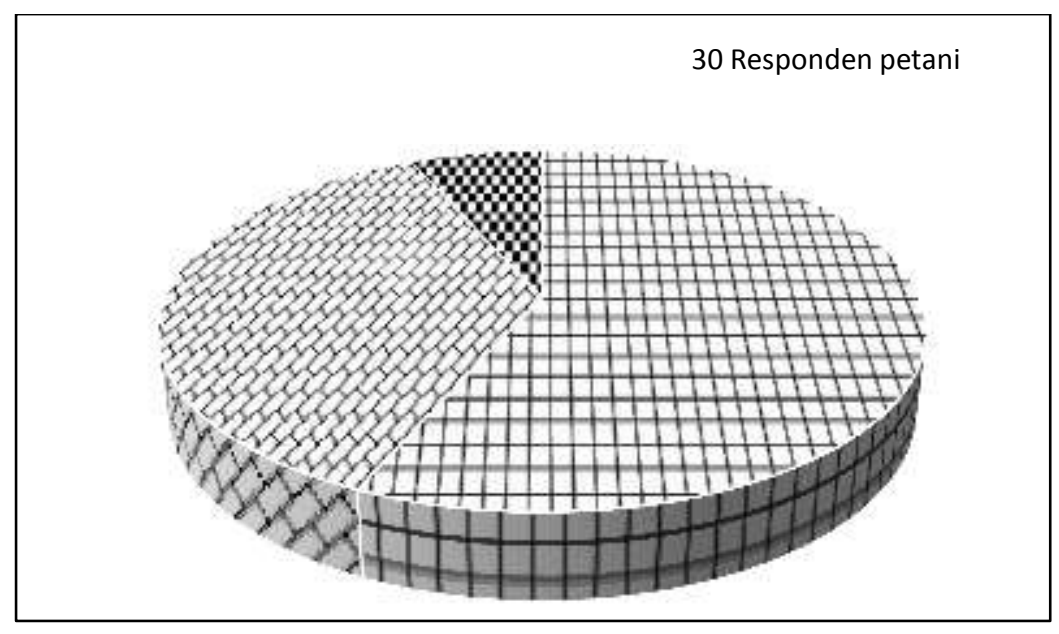

Gambar 1. Distribusi responden berdasarkan luas penanaman bawang putih

Zaini, A.,Anwar, Zubair, M.,Sudjatmiko, D.P.,Suparmin, dan Sari, N.M.W. 


\section{Kinerja Wajib Tanam}

Berdasarkan kontrak Perjanjian Kerja Sama (PKS) antara pelaku usaha/importir dengan petani maka petani berhak mendapatkan bantuan bibit sebanyak 1.000 kilogram untuk setiap 1 hektar luas penanaman dan untuk sarana produksi lainnya senilai 15 juta rupiah. Atas semua bantuan tersebut petani wajib menyediakan lahan penanaman bawang putih yang memenuhi persyaratan agroklimat pada ketinggian lebih dari 800 meter dari permukaan laut dan menyediakan tenaga kerja terampil untuk melakukan kegiatan budidaya dan pasca panen. Sebagai imbalannya importir mendapatkan bagi hasil sebanyak 1500 kilogram bawang putih konde basah untuk setiap 1.000 kilogram benih/bibit yang diberikan. Selain itu importir berkewjiban memberikan bimbingan teknis dan administrasi selama proses produksi.

Hasil penelitian menunjukkan bahwa kinerja wajib tanam bawang putih sangat baik, dimana produksi rata-rata bawang putih yang diperoleh dari kegiatan wajib tanam mencapai 12,8 ton per hektar (bandingkan dengan asumsi 6 ton per hektar yang digunakan dalam Permentan 24/2018). Dari jumlah tersebut petani sebagai agent mendapatkan bagi hasil produksi bawang putih sebanyak 10.9 kilogram per hektar, sedangkan importir sebagai principal mendapatkan bagi hasil 1.9 kilogram yang akan diproses menjadi bibit untuk musim tanam berikutnya. Detail kinerja wajib tanam bawang putih oleh importir secara grafis disajikan pada gambar 2 berikut.

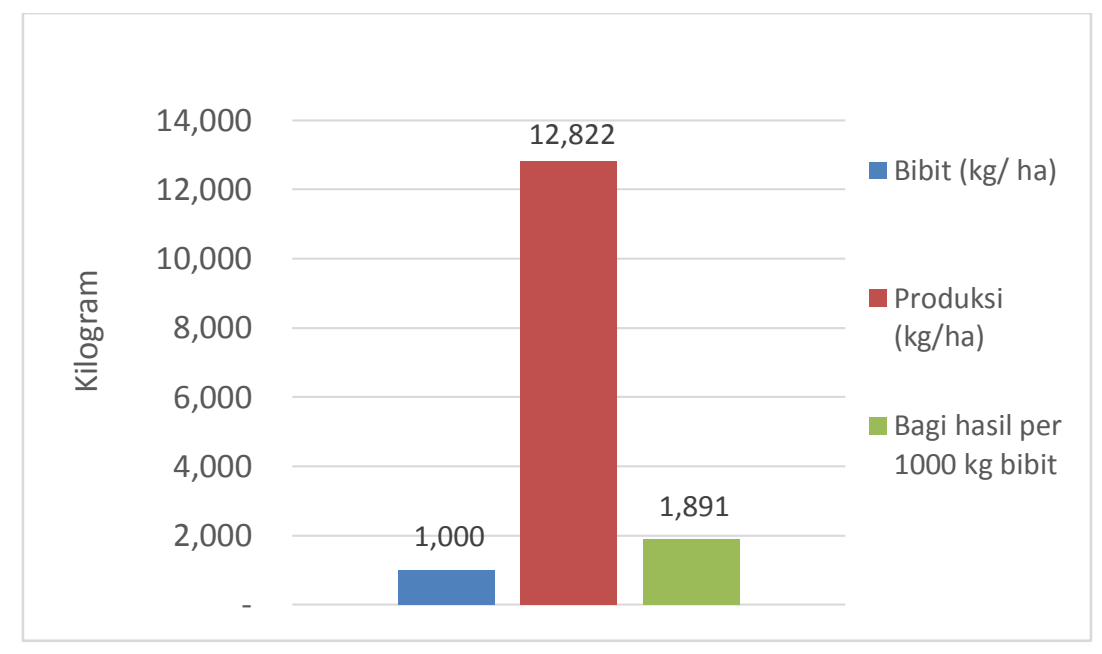

Gambar 2. Kinerja wajib tanam Bawang Putih oleh importir tahun 2020

\section{Analisis Model Principal-Agent}

Dengan disepakatinya kontrak perjanjian kerja sama maka importir menyerahkan kewajiban pengembangan bawang putih kepada petani. Dari sudut pandang teori Principal-Agent maka importir bertindak laksana principal yang memberi pekerjaan kepada petani (agent). Sebagai agent maka petani harus melakukan kegiatan penanaman sesuai permintaan principal, yaitu menanam bawang putih. Tujuan utama principal dari kerjasama ini adalah mendapatkan alokasi kuota impor bawang putih yang maksimum, hal ini sejalan dengan tujuan agent yaitu memaksimumkan produksi bawang putih. Oleh karena itu untuk lebih menjamin agar agent bertindak dan berusaha 
maksimal maka kontrak bagi hasil yang ditawarkan principal lebih banyak mempertimbangkan kepentingan agent. Oleh karena itu bagi hasil yang diterima principal hanya untuk memenuhi kebutuhan bibit pada musim berikutnya.

Formulasi kontrak bagi hasil yang menguntungkan agent di satu sisi dan tidak adanya kewajiban principal untuk membeli produksi bawang putih agent di sisi lain telah memberikan insentif menarik bagi agent untuk memaksimmkan produksi dan pada saat yang sama telah menghemat biaya monitoring oleh principal. Selain itu principal juga tidak dipersalahkan agent jika harga jual anjlok pada saat musim panen (Suara NTB, 2020). Dengan demikian maka model hubungan kerjasama ini telah memaksimumkan produksi namun terhindar dari persoalan moral hazard yang umumnya terjadi pada persoalan keagenan.

Dari sisi produksi, imlementasi wajib tanam bawang putih ini memberikan hasil sangat baik dimana produktivitas bawang putih mencapai 12,8 ton/ha. Bagi principal hal ini berarti kuota impor yang diperoleh saat mengajukan RIPH berikutnya adalah 12,8 ton dikali $(100 / 5)$ yaitu 256 ton untuk setiap hektar kegiatan wajib tanam. Jika keuntungan dari kegiatan impor bawang putih diasumsikan sebesar Rp. 5.000/kg (Tempo, 2020), maka importir akan mendapatkan keuntungan sebesar 1,28 milyar rupiah untuk setiap hektar wajib tanam. Sementara itu agent menerima bagi hasil sebanyak 10,9 ton, setelah dikurangi 1,9 ton bagian principal. Dengan harga jual ratarata saat panen sebesar 6.000 rupiah per kilogram maka agent memperoleh pendapatan sekitar 65 juta rupiah per hektar. Nilai ini jauh lebih besar dari pendapatan bersih menanam wortel sebesar 18,7 juta (Saefudin, 2018) ataupun kentang sebesar 41.5 juta (Fahrizal, 2019).

Berdasarkan petunjuk teknis pengembangan bawang putih oleh importir maka luas areal penanaman dan produksi yang diperoleh harus diketahui oleh pejabat Dinas Pertanian Kabupaten Lombok Timur. Namun dari hasil wawancara dengan pejabat dinas pertanian kabupaten, mereka tidak mengetahui hasil dari pelaksanaan wajib tanam tersebut. Hal ini terasa janggal karena salah satu fungsi dari dinas pertanian dalam pengembangan bawang putih adalah memfasilitasi dan mengkoordinasikan pelaksanaan kegiatan mulai dari tahap perencanaan hingga verifikasi atas laporan hasil panen. Oleh karena itu dari aspek monitoring dan evaluasi terdapat peluang dari para pihak untuk melakukan mark up data produksi sehingga importir memperoleh alokasi impor tinggi.

Selain itu hasil wawancara mendalam dengan petani dan pejabat dinas pertanian diperoleh informasi yang mengindikasikan terjadinya kompetisi antara importir dan Dinas Pertanian dalam memperoleh Calon Petani dan Calon Lahan (CP-CL) untuk pengembangan bawang putih. Dalam rangka peningkatan produksi bawang putih di Kabupaten Lombok Timur, pemerintah pusat dan daerah melalui jajaran kementerian dan dinas pertanian mengalokasikan anggaran pengembangan melalui APBN dan APBD. Untuk mencapai tujuan peningkatan produksi tersebut masing-masing pihak berupaya mendapatkan CP-CL pada zona 1 yaitu di Kecamatan Sembalun dimana infrastruktur dan petaninya sudah lebih maju dibandingkan CP-CL di zona 2 (Kecamatan Suela). Oleh karena itu dari aspek pengembangan wilayah diperlukan pembagian zona yang tegas antara wilayah pengembangan yang dilakukan oleh swasta dan pengembangan oleh pemerintah. 


\section{KESIMPULAN DAN SARAN}

Implementasi kebijakan wajib tanam bawang putih oleh importir di Kabupaten Lombok Timur dilakukan importir bekerja sama dengan petani yang dinyatakan secara tertulis dalam sebuah kontrak Perjanjian Kerja Sama (PKS). Dalam PKS tersebut pembagian hak dan kewajiban para pihak dinyatakan secara eksplisit sebagai acuan pelaksanaan pengembangan bawang putih.

Kinerja wajib tanam dari sisi produksi mencapai 12,8 ton per hektar dimana 85 persen dibagi untuk petani dan 15 persen untuk importir. Bagi hasil yang diterima importir ini kemudian diproses menjadi bibit untuk digunakan pada musim tanam berikutnya. Dari jumlah produksi tersebut importir akan mendapatkan alokasi impor sebanyak 256 ton untuk setiap hektar kegiatan wajib tanam sementara petani mendapatkan 10,9 ton dari bagi hasil.

Keuntungan harapan (expected profit) importir dari kegiatan wajib tanam adalah 1,28 miliar rupiah per hektar yang berasal dari kegiatan importasi sementara keuntungan harapan petani sebagai agent adalah 65 juta rupiah. Keuntungan yang diterima petani melalui kerjasama ini lebih besar dari keuntungan menanam tanaman alternatif terbaik lainnya seperti wortel dan kentang secara mandiri.

Untuk lebih menjamin keberhasilan program pengembangan bawang putih maka peran koordinasi dan verifikasi pemerintah melalui dinas pertanian agar lebih ditingkatkan. Selain itu pemisahan zona penanaman antara pengembangan yang dilakukan swasta melalui wajib tanam dengan dinas melalui dana APBN dan APBD agar lebih ditegaskan. Oleh karena fungsi pemerintah adalah fasilitator pengembangan maka areal di zona 1 yang infrastrukturnya lebih baik diutamakan untuk swasta sementara pemerintah melakukan pengembangan areal penanaman di zona 2 .

\section{DAFTAR PUSTAKA}

Bergman, M., \& Lane, J. E. (1990). Public policy in a principal-agent framework. Journal of Theoretical Politics, 2(3), 339-352.

Braun, D., \& Guston, D. H. (2003). Principal-agent theory and research policy: an introduction. Science and public policy, 30(5), 302-308.

Fahrizal, M. 2018. Prospek Pengembangan Usahatani. Kentang di Kecamatan Sembalun. Kabupaten Lombok Timur. Skripsi Sarjana. Fakultas Pertanian, Universitas Mataram.

Lane, J. E., \& Kivisto, J. A. (2008). Interests, information, and incentives in higher education: Principal-agent theory and its potential applications to the study of higher education governance. In Higher education (pp. 141-179). Springer, Dordrecht.

Maggetti, M., \& Papadopoulos, Y. (2018). The principal-agent framework and independent regulatory agencies. Political Studies Review, 16(3), 172-183.

Zaini, A.,Anwar, Zubair, M.,Sudjatmiko, D.P.,Suparmin, dan Sari, N.M.W. 
Nuppenau, E. A. (2002). Towards a genuine exchange value of nature: interactions between humans and nature in a principal-agent-framework. Ecological Economics, 43(1), 33-47.

Paez-Perez, D., \& Sanchez-Silva, M. (2016). A dynamic principal-agent framework for modeling the performance of infrastructure. European Journal of Operational Research, 254(2), 576-594.

Saefudin, 2019. Analisis Usahatani Wortel di Kecamatan Sembalun Kabupaten Lombok Timur. Skripsi Sarjana. Fakultas Pertanian, Universitas Mataram.

Shavell, Steven. 1979. Risk Sharing and Incentives in the Principal Agent Relationship. The Bell Journal of Economics, Vol. 10, No 1, pp 55-73.

Van Houten, P. (2009). Authority in multilevel parties: A principal-agent framework and cases from Germany and Spain. In Territorial party politics in Western Europe (pp. 167-182). Palgrave Macmillan, London.

Wohlstetter, P., Datnow, A., \& Park, V. (2008). Creating a system for data-driven decision-making: Applying the principal-agent framework. School effectiveness and school improvement, 19(3), 239-259. 